\title{
CERVICAL SCREENING ENGAGEMENT WITH MĀORI WOMEN: BARRIERS TO SCREENING AND THE ROLE OF THE NON-MĀORI NURSE
}

\author{
Georgia Hanson
}

\section{INTRODUCTION}

New Zealand is recognised globally for our kindness, equity and unity as a country. However behind this facade lies the stark reality of institutional and casual racism towards our indigenous population. Our healthcare system is no different. Māori are the most marginalised and deprived ethnic group in New Zealand healthcare (Theunissen, 2014). Of particular concern is the comparison between Māori and non-Māori cervical cancer incidence. As New Zealanders, we have access to an extremely effective screening tool that is proven to reduce the prevalence of cancer, yet in some areas merely half of our indigenous population engages with it. Engagement with screening services has a direct correlation to the incidence, mortality and survival of cervical cancer, so why are some Māori women not taking part? The answers lie in several substantial barriers that exist within our healthcare system, blocking Māori women from utilising screening, in turn harming the health and wellbeing of our wahine.

Non-Māori women do not experience the same prejudice, preconception and ignorance as Māori women do when partaking in smear tests, therefore a significant gap exists regarding screening rates between populations. Although this gap has decreased considerably in recent years, Māori women are still almost twice as likely to be diagnosed with the cervical cancer, and three times as likely to die from it (McLeod et al., 20 I0). While the issue of institutional racism and prejudice is circulating the world, we must do our part to collaborate with our indigenous population and do better. It is everyone's responsibility to provide safe and protective services to our wahine.

\section{BACKGROUND}

New Zealand has adequate screening compared to other developed countries. However, the disparity between our indigenous Māori population and non-Māori women who participate in screening programmes and attend smears tests is significant and concerning. Statistics reveal that the national three year coverage for Māori was just 67 percent as of January 2020, well below the majority population coverage of 75.6 percent (National Screening Unit, 2020). While there are many barriers that contribute to this disparity between Māori and non-Māori screening rates, there are three main obstacles that are predominantly responsible. The first obstacle is the Māori construct of whakamā - a concept encapsulating western ideals of shyness or embarrassment. Secondly, poor previous experiences in primary health care for Māori have also been identified as a major barrier, including but not limited to non-adherence to cultural safety guidelines supported by the Treaty of Waitangi for nurses in New Zealand and a disregard for Māori culture (Nursing Council of New Zealand, 20 II).

Finally, these obstacles are amalgamated with a fear and/or lack of knowledge surrounding cervical screening in Māori women caused by potentially poor health education, and/or a cultural stigma surrounding fertility and sexual health. Due to this compelling and undeniable evidence, which I will discuss in greater detail below, I believe that 
non-Māori nurses heavily contribute to these barriers to cervical screening engagement in Māori women and in turn, profoundly impact on the health and wellbeing of our wahine in New Zealand. Collaboration between Māori and non-Māori nurses and patients is required to improve cervical screening services for our Māori population, as this issue is the responsibility of all health care professionals in New Zealand.

\section{BARRIERS TO SCREENING}

\section{Whakamā}

Whakamā is a Māori construct encapsulating concepts of shyness, embarrassment and modesty (Sachdev, 1990), and is proven to be a key barrier to cervical screening for Mãori women. As our health system is largely based on a westernised view of health, we often fail to acknowledge and understand why invasive procedures are difficult for Māori women to participate in - however it is worth noting that not all Māori women will share the same cultural beliefs in contemporary New Zealand today. The cervix is the doorway to te wharetangata (Home of humanity, or the womb) and is traditionally considered extremely tapu (sacred) in Māori culture (Lewis, 2009). Smear tests are exceedingly invasive procedures that expose women, which may be emphasised even more for traditional Māori women when considering how the sacredness of sexuality and fertility is being violated during the screening process. Generally, non-Māori health providers fail to realise that examinations and sexual health conversations are tapu (Cook, Clark \& Brunton, 2014). Being tapu, cervical health and screening may not always be directly discussed within their hapū (traditionally a grouping of whānau connected by a common ancestor) which may further contribute to feelings of whakamā about their own health and screening (Scott-Melton, 2019). Other Māori concepts that may contribute to whakamā are those of Mana Wahine. Mana Wahine reflects Māori womens' connection to the land as descendants of Papatūānuku (Lewis, 2009), and links in with the concept of previously mentioned te wharetangata (house of humanity, a woman's womb). Both Mana Wahine and Te Wharetangata are concepts at the centre of whānau, hapū and iwi (historically, subgroups within Māori culture who share ancestors and common land (Te Ara, 2005) - emphasising the sacredness of the female reproductive system and the invasiveness of smear tests, particularly if performed in a culturally unsafe manner (Lewis, 2009). A disregard for Māori culture by non-Māori practitioners during such an invasive procedure, which Māori may deem as sacred, is a huge barrier which prevents Māori women accessing and engaging with screening services.

Traditionally Māori have a more holistic view on health and wellbeing than our predominantly westernised health system - though this is a generalisation as not all Māori will have identical beliefs and knowledge in contemporary New Zealand. The traditional Māori view of health can be better understood using the Te Whare Tapa Whā model developed by Mason Durie (Ministry of Health, 2017), which encompasses the four cornerstones of health Taha Wairua (spiritual wellbeing), Taha Hinengaro (mental/emotional wellbeing), Taha Tinana (physical wellbeing), and Taha Whanāu (relationships/family). All four cornerstones are considered equally important and must all be addressed to ensure total wellbeing. Our westernised health system often fails to acknowledge this holistic view and consequently fails Māori in their health outcomes. Examples of such oversights in a cervical screening context include having no option to clean yourself before a smear test (water is a symbol of life and purification in Māori culture, which could decrease a women's anxiety before a smear) as well as incidents occurring that can deeply violate a women's privacy during a smear test, such as being exposed for prolonged periods of time e.g. while a clinician has a discussion (Buetow et al., 2007). A collaborative approach to health combining both western and Māori views is required to ensure that cultural needs and preferences are adhered to for both our indigenous and non-indigenous populations in New Zealand. 


\section{Non-Māori Practitioners and Poor Previous Experiences for Māori Women}

Ethnocentrism is broadly defined as thinking that one's own group and their 'ways' are superior to others or judging another group as being inferior to their own (Barger, 2019). Barger (2019) states that ethnocentrism is based on making false assumptions about others' ways of living, due to our own limited experience, however, argues that it is likely we are unaware we are being ethnocentric all the time. Ethnocentrism can be an issue in the delivery of healthcare to Māori women. Non-Māori nurses must be aware of their own cultural experiences and challenge the assumptions they make based off of these experiences, which is outlined in Principle three of the Nursing Council of New Zealand Cultural Safety Guidelines (20II) as; "understanding the impact of the nurse as a bearer of his/her own culture, history, attitudes and life experiences..." (p.8). Failing to do so results in decreased engagement with cervical screening services due to poor previous experiences for Māori women. Non-Māori nurses must collaborate and learn from their Māori counterparts to ensure the care provided is based on the patient's best interests rather than an ethnocentric assumption from personal experiences.

Māori have the poorest health status of any ethnic group in New Zealand, across all specialities and services (Curtis et al., 2019). While registered nurses are expected to abide by the guidelines set out in the Treaty of Waitangi to ensure culturally safe and protective experiences for Māori (Nursing Council of New Zealand, 201I), other regulatory bodies are responsible for the determination of cultural safety in each respective health profession. Despite this, a disregard for the spiritual significance of areas of the body associated with sexuality and fertility by non-Māori nurses, and non-compliance to cultural safety expectations for Māori is certainly a barrier and deterrent for Māori women seeking healthcare (Cook, Clark, \& Brunton, 2014). Curtis et al. (2019) stated that cultural safety involves acknowledging barriers to clinical effectiveness which arise from the power imbalance between provider and patient, it seeks to "achieve better care through being aware of difference, decolonising, considering power relationships, implementing reflective practice, and by allowing the patient to determine whether a clinical encounter is safe" (p.4).

Poor experiences in New Zealand health care are all too common for Māori women, and have a strong impact on their future decisions to engage with healthcare services as shown in a study from Harris et al. (2012) where racial discrimination by a health professional was associated with lower rates of cervical screening in Māori women. Negative screening experiences (experienced either personally or relayed by trusted older women) also leave women with a reluctance to be screened/screened again (Scott-Melton, 2019). This shows that these challenging experiences have a ripple effect and can impact not only one woman, but those women within her hapu as well. Although primary healthcare providers generally endeavour to have indigenous nurses available, Māori are underrepresented in health professions (Cook, Clark \& Brunton, 2014).

This under-representation subsequently results in Māori not having a choice of providers and often having nonindigenous and potentially culturally unsafe nurses performing extremely invasive procedures (such as smear tests), who are unable to appreciate the sacredness and cultural significance for Māori. It is noted that health practitioners not taking time to discuss the procedure and emphasise the importance of cervical screening, not formally asking for consent or assuming that consent is gained by patients simply coming to the appointment, and pressuring women into smears through opportunistic screening are common negative experiences for Māori women (ScottMelton, 2019). Across many articles it is articulated that Māori women value feeling welcomed and cared for during their primary health experience (mihi), noting that staff who make the experience purely clinical without taking brief time to greet and settle their patients (kaupapa) made women feel uncomfortable, vulnerable, and was a predictor of the entire experience being negative (Cook, Clark \& Brunton, 2014). 


\section{FEAR AND LACK OF KNOWLEDGE}

Lack of information is a common barrier for all screening services globally, and cervical screening is no exception. Findings show that a lack of knowledge about cervical cancer andcervical cancer screening and services, prove to be a major barrier for getting women to engage with said services (Scott-Melton, 2019). As previously discussed, te wharetangata is tapu, and therefore cervical health is likely not discussed within a more traditional woman's hapū. Due to this cultural context, what younger Māori women learn about cervical health comes from within their own whānau and communities, particularly from older women. If these experiences are discussed in a negative manner, including accounts of pain and discomfort, it is likely that young women will have negative connotations towards smear tests without ever having had one themselves. In a study conducted in 2019, young Māori women expressed that they didn't understand why they required screening, had very basic knowledge of their own anatomy - including where the cervix was - and had limited knowledge about how Human Papillomavirus (HPV) impacts on their cervical health, or if they had received their HPV vaccination (Scott-Melton, 2019). There are continuous accounts of situations where patients felt confused due to poor health literacy/lack of explanation and negative communication/interactions with a health provider, resulting in patients who disengaged with health services. The unfortunate fact that these experiences are so common emphasises the importance of both Māori and non-Māori practitioners collaborating to empower Māori patients to feel confident and informed, which will in turn ensure increased engagement with health services (McLeod et al., 20II). Adequate education about the need for screening, cervical health, and what screening involves is fundamental for improving Māori engagement with screening programmes. Reductions in disparities between Māori and non-Māori for cervical cancer are partly due to greater awareness of cervical cancer and screening (McLeod et al., 20II). Multiple modes of communication, the inclusion and promotion of Māori health providers and increased face-to-face communication (kanohi ki te kanohi) between provider and patient were all identified as having improved awareness amongst Māori (McLeod et al., 20II).

\section{RECOMMENDATIONS}

Research projects are currently underway in New Zealand to understand how a self-test may work for priority populations who require cervical screening. Adcock et al, (2019) explored the acceptability of a HPV self-test among Māori women as a possible alternative to smear tests. It has been established that the cost of attending a clinic and the invasiveness of a pelvic examination are other existing barriers to Māori women attending cervical screening appointments - an at home self-test removes both of these barriers (Adcock et al., 2019). The study involved hui with Māori women of both rural and urban origins who had reported not screening for 4+ years, and resulted in 397 eligible women completing the survey. The women in the hui most frequently referred to a desire for body autonomy as a primary reason for not attending regular screening, encompassing concepts of whakamā and tapu (Adcock et al., 2019). Overall, 73.3 percent of the participants stated they were likely/very likely to self-test if it was offered, and 77.8 percent stated they would be happy to perform the test in their own home (Adcock et al., 2019). The majority of the women who participated in the study were engaged in the health system but did not screen, thus proving a system failure. The findings from the study suggest that HPV self-testing could be a very acceptable and appropriate option for under/never screened Māori women (Adcock et al., 2019). Recommendations that surfaced from the study for a culturally competent prevention programme were, adequate HPV education with a whānau approach, empathetic delivery of services and flexibility within the programme to provide multiple options for Māori women, for example, at home option, in-clinic education or targeted outreach (Adcock et al., 2019). This is a viable option to implement in our primary health care system, as it directly removes several of the main barriers to screening. Furthermore, this option allows Māori women to take back power from non-Māori clinicians by collaborating to improve their own health. Performing a self-test at home allows patients to remain autonomous with their bodies and preserves the sacredness of te wharetangata. Moreover, it removes whakamā and stress from the encounter and provides an opportunity for comprehensive health education to ensure sufficiently informed consent. Implementing more rigorous cultural safety training and regularly reviewing a 
practitioner's ability to be culturally safe is vital to improving Māori health outcomes - this is currently achieved for nurses in Aotearoa when renewing one's practicing certificate. It is clear from the evidence that culturally unsafe practices continue to be an enormous issue within our health system and contributes to all barriers discussed for Māori women accessing healthcare, despite efforts to enforce cultural safety guidelines. Many registered and enrolled nurses within New Zealand currently fail to acknowledge or understand Māori health concepts which are crucial when undertaking invasive procedures such as smear tests, instead making ethnocentric assumptions about the care they are delivering.

Cultural safety competence is reviewed annually for nurses; however, this should be a requirement for all health professionals. Nurses in New Zealand should be educated on Māori health beliefs and where they stem from, to gain a better understanding of the differences in Māori and non-Māori health views as well as the importance of maintaining cultural safety during invasive procedures. Non-Māori nurses must understand that collaboration between western and Māori health concepts will provide a safer, more holistic service for all. Cook et al, (20l4) suggested that in order to provide culturally safe experiences, health providers must ensure they recognise Māori women as whole beings, that strong relationships are built between women and staff to enable trust, that communication is recognised and prioritised and that responsive listening is actively practiced. These actions encompass culturally safe practices and promote therapeutic relationships between Māori and non-Māori.

\section{CONCLUSION}

Māori having the worst health outcomes of any ethnic group in New Zealand reflects the failures of our health system. We are failing our indigenous women and depriving them of culturally competent, effective care that is virtually guaranteed to protect them from cervical cancer. Non-Māori practitioners are certainly either solely responsible for, or majorly contribute to all of the barriers discussed above. An element of institutional racism in the New Zealand healthcare system towards Māori patients, a general lack of appreciation and adherance to cultural safety guidelines, and an element of ethnocentrism from nurses are all factors that contribute to the barriers that impact on the health of our indigenous population - including cervical screening engagement. Collaboration is required so we can learn from our indigenous counterparts how we can improve our own practice to protect the women of our country.

Historically the burden of Māori health issues is placed on healthcare providers that identify as Māori or Māori health providers. However I believe that it is the responsibility of all healthcare providers to ensure Māori women have safe and appropriate encounters at all levels. It is an individual issue that we must expel.

\section{ACKNOWLEDGEMENTS}

Thank you to Kate Hanson, for reading and providing excellent feedback.

Georgia Hanson is a third-year student completing her Bachelor of Nursing at Otago Polytechnic, Dunedin New Zealand. She is passionate about the aspects of nursing where she feels that she can help and care for patients, family and whānau. She believes that the nursing profession provides people with empowerment, compassion, and a therapeutic environment that allows for healing and growth.

Correspondence to: Georgia Hanson: School of Nursing, Otago Polytechnic | Te Kura Matatini ki Otago, Forth Street, Private Bag 1910, Dunedin 9054, New Zealand. Email: georgia-hanson@hotmail.com 


\section{REFERENCES}

Adcock, A., Cram, F., Lawton, B., Geller, S., Hibma, M., Sykes, P., Macdonald, E. J., ... Hart, S. (2019). Acceptability of self-taken vaginal HPV sample for cervical screening among an under-screened Indigenous population. Australian and New Zealand Journal of Obstetrics and Gynaecology, 59(2), 301-307. DOI: 10.1III/ajo.12933

Barger, K. (2019). Ethnocentrism. Retrieved from https://anthkb.sitehost.iu.edu/ethnocen.htm

Beutow, S., Janes, R., Steed, R., Ihimaera, L., \& Elley, C. R. (2007). Why don't some women return for cervical smears? A hermeneutic phenomenological investigation. Health Care for Women International, 28(9), 843-852. DOI: 10. I080/0739933070 I56325I

Cook, C., Clark, T., \& Brunton, M. (2014). Optimising cultural safety and comfort during gynaecological examinations: Accounts of Indigenous Mãori Women. Nursing Praxis in New Zealand, 30(3), 19-34.

Curtis, E., Jones, R., Tipene-Leach, D., Walker, C., Loring, B., Paine, S.J., \& Reid, P. (2019). Why cultural safety rather than cultural competency is required to achieve health equity: A literature review and recommended definition. International Journal for Equity in Health, 174(18), 2-17. DOI: 10.1186/s12939-019-1082-3

Harris, R., Cormack, D., Tobias, M., Yeh, L.C., Talamaivao, N., Minister, J., \& Timutimu, R. (20I2). Self-reported experience of racial discrimination and health care use in New Zealand: Results from the 2006/07 New Zealand health survey. American Journal of Public Health, 102(5), I0I2-I019. DOI: 10.2105/AJPH.2011.300626

Lewis, H. (2009). Cervical smears - achieving equity. Best Practice Journal, (23). Retrieved from https://bpac.org.nz/BPJ/2009/ September/docs/bpj23_csmears_pages46-55.pdf

McLeod, M., Cormack, D., Harris, R., Robson, B., Sykes, P., \& Crengle, S. (20II). Achieving equitable otucomes for Māori women with cervical cancer in New Zealand: Health provider views. Journal of the New Zealand Medical Association, 124(I334), 52-62.

McLeod, M., Harris, R., Purdie, G., Cormack, D., Robson, B., Skyes, P., Crengle, S., ... Walker, N. (20I0). Improving survival disparities in cervical cancer between Māori and non-Māori women in New Zealand: A national retrospective cohort study. Australian and New Zealand Journal of Public Health, 34(2), 193-199. DOI: 10.1 II I/j.1753-6405.2010.00506.x

Ministry of Health. (2017). Māori health models - Te Whare Tapa Whā. Retrieved from https://www.health.govt.nz/our-work/ populations/maori-health/maori-health-models/maori-health-models-te-whare-tapa-wha

National Screening Unit. (2020). National cervical screening programme coverage report. Retrieved from https://minhealthnz. shinyapps.io/nsu-ncsp-coverage/

Nursing Council of New Zealand. (2011). Guidelines for cultural safety, the Treaty of Waitangi and Mãori health in nursing education and practice. Author. Wellington, New Zealand.

Sachdev, P. S. (1990). Mental health and illness of the New Zealand Maori. Transcultural Psychiatric Research Review, 27(2), 85- III.

Scott-Melton, F. (2019). Cervical screening communications for young Mãori, Pacific and Asian women. Wellington, New Zealand: Allen + Clark.

Te Ara - The Encyclopedia of New Zealand. (2005). Tribal organisation - the significance of hapu and iwi. Retrieved from https:// teara.govt.nz/en/tribal-organisation/page-।

Theunissen, K. E. (2014). The nurse's role in improving health disparities experienced by the indigenous Māori of New Zealand. Contemporary Nurse, 39(2), 28I-286. https://doi.org/I0.5172/conu.2011.39.2.281 